\title{
PSYCHOLINGUISTICS: A CROSS-LANGUAGE PERSPECTIVE
}

\author{
Elizabeth Bates \\ University of California, San Diego \\ Antonella Devescovi \\ University of Rome 'La Sapienza'
}

Beverly Wulfeck

San Diego State University and University of California, San Diego

Technical Report CRL-0009

May 2000

Center for Research in Language

University of California, San Diego

La Jolla, CA 92093-0526

Annual Review of Psychology, 2001, 52, 369-396 


\title{
PSYCHOLINGUISTICS: A CROSS-LANGUAGE PERSPECTIVE
}

\author{
Elizabeth Bates \\ University of California, San Diego \\ Antonella Devescovi \\ University of Rome 'La Sapienza' \\ Beverly Wulfeck
}

San Diego State University and University of California, San Diego

Support was provided by "Cross-linguistic studies of aphasia" (DC00216), "Center for the Study of the Neural Bases of Language \& Learning" (NS22343), "Origins of Communication Disorders" (DC01289). Thanks to Meiti Opie for assistance in manuscript preparation. Please address all correspondence to Elizabeth Bates, Center for Research in Language, Dept. 0526, University of California, San Diego, La Jolla, CA 92093 (bates@crl.ucsd.edu). 


\title{
PSYCHOLINGUISTICS: A CROSS-LANGUAGE PERSPECTIVE
}

\author{
Elizabeth Bates, Antonella Devescovi, and Beverly Wulfeck
}

\begin{abstract}
Cross-linguistic studies are essential to the identification of universal processes in language development, language use and language breakdown. Comparative studies in all three areas are reviewed, demonstrating powerful differences across languages in the order in which specific structures are acquired by children, the sparing and impairment of those structures in aphasic patients, and the structures that normal adults rely upon most heavily in real-time word and sentence processing. It is proposed that these differences reflect a cost-benefit trade-off among universal mechanisms for learning and processing (perception, attention, motor planning, memory) that are critical for language, but are not unique to language.
\end{abstract}

The purpose of psycholinguistic research is to uncover universal processes that govern the development, use and breakdown of language. However, to the extent that research in a given subfield of psycholinguistics is dominated by English, we cannot distinguish between universal mechanisms and English-specific facts. Below we will present a brief and selective review of cross-linguistic research on language development in children, language symptoms in braininjured adults, and language processing in normal adults, in an order that reflects the impact that crosslanguage variations have had on theoretical frameworks within each field.

Cross-linguistic studies of monolinguals come in two varieties. ${ }^{1}$ One approach treats language as a between-subjects variable, applying the same experimental design in two or more languages to determine how theoretically relevant linguistic differences affect performance. Examples from child language include cross-linguistic comparisons of tense and aspect in narratives (Berman \& Slobin 1994), the use of "path verbs" vs. "manner verbs" to describe an action-packed cartoon (Slobin 1996), the acquisition of spatial locatives (Bowerman \& Choi 1994), and differential use to word order, semantics and grammatical morphology to assign agent-object relations in a "Who did the action?" task (Bates et al., 1999; Devescovi et al., 1998, MacWhinney \& Bates 1989, Slobin \& Bever 1982). Studies of aphasia from this perspective are summarized in Bates et al. (1991b). Studies of word and sentence processing in normal adults that treat language as a between-subjects variable are reviewed in MacWhinney \& Bates (1989) and Hillert (1998).

A second approach treats languages as experiments of nature, exploiting particular properties of a single target language to ask questions that could not be answered in (for example) English. A host of child language studies from this point of view are summar-

\footnotetext{
${ }^{1}$ Because of length limitations, this review is restricted entirely to research on monolinguals. However, the literatures on bilingual development, bilingual aphasia, and processing in bilingual adults are certainly relevant to basic science in psycholinguistics, especially those studies that treat the contrast between a bilingual's two languages as a withinsubjects variable.
}

ized in Slobin's 5-volume work, The cross-linguistic study of language acquisition (Slobin 1985-1997), most of them emphasizing the analysis of free speech (see also Sokolov \& Snow 1994, and virtually any volume of Journal of Child Language). Case studies of speech production in agrammatic Broca's aphasics in many different languages can be found in Menn and Obler (1990). An increasing number of descriptive and/or experimental studies of aphasia in various languages can be found in the journal Brain and Language. Finally, studies of word and sentence processing in healthy adult native speakers of languages other than English have increased in frequency in the last few years, including special issues devoted to the processing of morphology (Sandra \& Taft 1994), and grammatical gender (Friederici et al. 1999).

Studies from both points of view will be considered here. But first, let us consider some concrete examples of structural contrasts with powerful implications for psycholinguistic theory, and use them to illustrate how cross-linguistic research can be used in the search for universal mechanisms.

\section{Cross-Language Contrasts and their Relevance for Processing}

We assume that psycholinguistic universals do exist. Languages like English, Italian and Chinese draw on the same mental/neural machinery. They do not "live" in different parts of the brain, and children do not differ in the mechanisms required to learn each one. However, languages can differ (sometimes quite dramatically) in the way this mental/neural substrate is taxed or configured, making differential use of the same basic mechanisms for perceptual processing, encoding and retrieval, working memory, and planning. It is of course well known that languages can vary qualitatively, in the presence/absence of specific linguistic features (e.g. Chinese has lexical tone, Russian has nominal case markers, English has neither). In addition, languages can vary quantitatively, in the challenge posed by equivalent structures (lexical, phonological, grammatical) for learning and/or realtime use. For example, passives are rare in English, but extremely common in Sesotho, and relative clause constructions are more common in English than Italian. To the extent that frequency and recency facilitate structural access, these differences should result in 
earlier acquisition and/or a processing advantage. As we shall see later, this seems to be the case for passives in Sesotho, and for relative clauses in Italian.

Holding frequency constant, equivalent lexical, phonological and/or grammatical structures can also vary in their reliability ("cue validity") and processibility ("cue cost"). These two constructs figure prominently in the Competition Model (Bates \& MacWhinney 1989, MacWhinney 1987), a theoretical framework developed explicitly for cross-linguistic research on acquisition, processing and aphasia. Like other interactive-activation or constraint-based theories, the Competition Model assumes parallel processing, with detailed and bidirectional interactions among different information types. Within this framework, cue validity refers to the information value of a given phonological, lexical, morphological or syntactic form within a particular language, while cue cost refers to the amount and type of processing associated with the activation and deployment of that form (e.g. perceivability, salience, neighborhood density vs. structural uniqueness, demands on memory, demands on speech planning and articulation). These two principles co-determine the nature of linguistic representations in a particular language and the nature of the dynamic processes by which form and meaning are activated and mapped onto each other in real time. Linguistic information is represented as a broadly distributed network of probabilistic connections among linguistic forms and the meanings they typically express, as in other connectionist theories of language. Linguistic rules are treated as form-meaning and formform mappings that can vary in strength, in that the " "same" rule may be stronger in one language than it is in another. Within a given language, structures that are high in cue validity should be the ones that normal adults attend to and rely upon most in real-time language processing, and they should also be acquired earlier by children and retained under stress by aphasic patients. However, effects of cue validity may be reduced or amplified by variations in cue cost, especially in young children and/or brain-injured patients whose processing costs are already very high.

To illustrate contrasts in cue validity, consider some of the factors that influence sentence interpretation (especially agent-object relations, or "Who did what to whom") in English, Italian and Chinese. In English, subjects are obligatory in free-standing declarative sentences (including dummy subjects like "it" in "It is raining"), and word order is preserved with a rigidity that is unusual among the world's languages. By contrast, Italian is a "pro-drop" language in which it is possible to omit the subject if it can be inferred from the context, or from markings on the verb (e.g. the best translation of "It is raining" in Italian, is "Piove," or "Rains"). Italian also permits extensive variation in word order for pragmatic purposes (e.g. it is possible to say "La lasagna (la) mangia Giovanni," or "The lasagna (it) eats Giovanni," with the normal reading in which people eat pasta, not the other way around). Because of these contrasts, word order (e.g. Noun-Verb-Noun) is a highly reliable cue to agent-object relations in English but a relatively poor cue in Italian.

In direct contrast with the situation for word order, subject-verb agreement is a weak cue to agent-object relations in English, but a powerful cue in Italian. For example, English has only two contrasting inflected forms in the present indicative paradigm (singular: I EAT, YOU EAT, HE EATS; plural: WE EAT, YOUALL EAT, THEY EAT), compared with six in Italian (singular: IO MANGIO, TU MANGI, LUI MANGIA; plural: NOI MANGIAMO, VOI MANGIATE, LORO MANGIANO). Looking at the full verb paradigm, Italian verbs can take up to 47 different forms, compared with only five in English (e.g. EAT, EATING, EATS, ATE, EATEN). Such extensive verb marking provides the listener with a rich source of information about "Who did what to whom" that is not available in English.

In contrast with both English and Italian, Chinese has no inflectional paradigms at all (e.g. no plural inflections on nouns or tense inflections on verbs). It does have function words and particles to convey some of the functions carried out by inflections in other languages. However, these particles come in a single unalterable form, are optional in all but a handful of contexts, and most are homophones or near-homophones of the content words from which they were historically derived (e.g. past-tense particle "wan" also means "to finish"). Despite the absence of case or agreement markers to indicate agent-object relations, word order is flexible in Chinese, and both subject and object can be omitted. As a result, a sentence literally translated as "Chicken eat" could mean "The chicken is eating" or "Someone is eating the chicken." Because of all these factors, Chinese listeners have to make flexible and rapid use of many different sources of information in sentence processing, including aspects of prosody, semantics and pragmatics that are less important in English or Italian.

These contrasts have clear implications for sentence-level processing (with effects that are discussed below), but they also interact with cross-linguistic differences in word structure to affect lexical access. This includes cross-language differences in lexical ambiguity, and differences in lexical structure that challenge the oft-cited distinction between words and rules (Pinker, 1999).

With regard to lexical ambiguity, the rich inflectional morphology of Italian makes it relatively easy to distinguish between nouns, verbs and other grammatical classes. In contrast, the sparse grammatical morphology of English means that nouns, verbs and other word classes often sound alike, and must be disambiguated by context ('the comb' vs. 'to comb'), or by prosodic cues ('to record' vs. 'the record'). In 
Chinese, the absence of inflectional morphology means that the potential for lexical ambiguity is even greater than it is in English. Some of this ambiguity is reduced in Chinese by lexical tone in the auditory modality (Cutler \& Chen 1997), and by the one-tomany mapping between syllables and the nonalphabetic characters that represent them in the written modality (Chen \& Tzeng 1992, Chen \& Zhou 1999). However, ambiguity is also affected by the rich sublexical structure of Chinese, due to the dominance and productivity of compounding. More than $80 \%$ of Chinese words are compounds (65\% disyllabic), and the syllables that comprise them occur in many other words. Hence most words are highly ambiguous on the first syllable, and many are not resolved until the end of the final syllable. A further complication lies in the fact that Chinese compounds and the morphemes inside them can belong to different form classes, including VN compounds that can either be nouns ('zipper'='lalian', literally 'pull-chain') or verbs ('to forge'='da-tie', literally 'strike-iron'). As a result, it is not always clear in Chinese whether we are dealing with a compound word (stored in the lexicon) or a novel noun or verb phrase (compiled on-line) (for a discussion, see Bates et al. 1991a, 1993 and Zhou et al. 1993).

With regard to the distinction between words and rules, English morphology and orthography are both highly irregular, a fact that has shaped theories of processing in both domains. To deal with the regularirregular contrast, "dual route" or "dual mechanism" theories propose that regular forms are handled by a rule-based system, including grammatical rules in morphology (Pinker 1999, Ullman et al. 1997), and phonological rules in reading (i.e. grapheme-phoneme correspondence rules-Coltheart et al. 1980). In these theories, irregular or exception forms are handled by rote memory (lexical look-up in morphology; 'whole word' access in reading), or by a limited neural network that is capable of generated new forms by analogy (Pinker 1999). Evidence cited in favor of dual-route models includes differential patterns of acquisition in children, dissociations in brain-injured patients, and differential processing of regulars and irregulars in normal adults. An alternative account is provided by connectionist or interactive-activation theories, in which the same differential patterns for regulars and irregulars are explained by domain-general dimensions like frequency, similarity and set size (Rumelhart \& McClelland 1986). Evidence for this alternative view is provided by neural network models in which regularirregular contrasts (including double dissociations) are simulated within a single architecture (e.g. Hinton \& Shallice 1991, Joanisse \& Seidenberg 1999, Juola \& Plunkett 1998, Marchman 1993, McClelland \& Seidenberg 1989, Plaut et al. 1996).

The dual-mechanism debate takes a different form when we move outside the boundaries of English. For example, Italian orthography is extremely transparent (i.e. direct grapheme-phoneme correspondence), but its morphology involves many irregular inflections. This irregularity is often a matter of degree, with multiple subregularities and partially productive patterns that pose an interesting challenge for dual-mechanism theories (Orsolini \& Marslen-Wilson 1997). Applying the dual-mechanism view to Italian, some proponents of the modular view (Say \& Clahsen 1999) have proposed that the '-are' conjugation class in Italian is 'regular' (handled by the grammar), but the other two classes ('-ire', '-ere') are irregular. However, this also means that the lexicon contains many highly productive conjugation patterns, an intellectual move that blurs the word-rule dichotomy. Such 'in-between' cases would be easier to handle if regularity were the product of continuous dimensions like frequency and similarity, as proposed by some connectionist accounts.

Chinese poses an even greater challenge to dualmechanism theories, because the regular-irregular distinction simply does not apply (at least in its original form) to reading in a language without an alphabet, or to grammar in a language with no inflectional paradigms. However, there may be analogues to regularity within the lexicon itself, ranging from 'regular' compound patterns (many members, low in frequency and similarity) to irregular or idiosyncratic compound patterns (few members, high in frequency and similarity). To the extent that this kind of regular-irregular distinction can be demonstrated within the lexicon itself, we have to question the English-based assumption that regulars are handled by rules (grammatical and/or phonological) while irregulars are handled in the lexicon (Ullman et al. 1997).

We are not suggesting that some languages are inherently harder to learn, process or retain under brain damage than others. All languages must have achieved a roughly comparable degree of "learnability" and "processibility" across the course of history, or they would not still be around. However, overall processibility is the product of cost-benefit trade-offs, a constraint satisfaction problem that must be solved across multiple dimensions of the language system. As a result, we may obtain powerful differences between languages in the relative difficulty of specific linguistic structures, with differential effects on performance by children, aphasic patients and healthy normal adults. I will also contend that this kind of cross-language variation in structural difficulty reflects universal facts about perception, learning and processing that are not specific to language at all.

\section{Cross-linguistic variations in language development \\ Speech perception. Human newborns are} "citizens of the world" (Kuhl 1985), able to discriminate virtually all of the sound contrasts (phonetics) that are used systematically by the world's languages (for a detailed review, see Aslin et al. 1998). Nevertheless, preferential-listening studies have shown that newborn infants have already acquired a weak preference for the 
sounds of their native language in utero (Jusczyk et al. 1993, Mehler et al. 1988), although the basis for this preference is still unknown. By 3 months of age, infants show selective preference for their own names, with discrimination of many detailed and languagespecific phonotactic features following soon thereafter (Jusczyk 1997), including a clear preference for the "prototypic vowels" of their native language by six months of age (Kuhl et al. 1992). Although such evidence for rapid learning of speech-specific structure was initially cited as evidence for the existence of a domain-specific "speech acquisition device" (Mehler et al. 1988), recent demonstrations of rapid statistical induction in 7-8-month-old infants (e.g. Marcus et al. 1999, Saffran et al. 1996), including results with nonspeech stimuli (Haith 1994, Saffran et al. 1997), have led some theorists to conclude that the infant brain is a powerful learning device that is capable of rapid learning from arbitrarily sequenced materials in any modality (e.g. Bates \& Elman 1996, Elman \& Bates 1997). Hence the acquisition of speech contrasts in the first year of life may be a language-specific manifestation of domain-general learning mechanisms (Kuhl 1985).

As a result of these findings, recent research in the development of speech perception has focused not only on the continued acquisition of language-specific preferences (Kuhl 1994), but also on the corresponding suppression of phonetic contrasts that are not used systematically in the child's linguistic input (e.g. the process by which Japanese infants lose the ability to hear "ra" vs. "la") (Polka \& Werker 1994, Werker \& Tees 1984). "Tuning in" to language-specific speech contrasts appears to be related systematically (and perhaps causally) to "tuning out" of phoneme contrasts outside of the child's language, a process that begins around 8-10 months of age. The timing of this "linguistic xenophobia" is probably no accident, since it co-occurs with the onset of systematic evidence for word comprehension. Indeed, such "learned inhibition" (which continues unabated for many years in a monolingual environment) may be at least partially responsible for the oft-cited observation that adults find it difficult to acquire a second language without an accent (McClelland et al. 1999).

Speech production. Despite ample evidence for the early acquisition of language-specific contrasts in speech perception, we know relatively little about the emergence of corresponding contrasts in speech production. For most children, canonical or reduplicative babbling begins between 6-8 months, with short segments or longer strings that are punctuated by consonants (e.g. "dadada"). Boysson-Bardies and colleagues (1984) have reported that babbling "drifts" toward the particular sound patterns of the child's native language between 6-10 months (i.e. native speakers can discriminate at above-chance levels between babble by Chinese, Arabic, English or French infants). However, the phonetic basis of these adult judgments is still unknown. Critics of this research have argued that there are hard maturational limits on the infant's ability to control the detailed gestures required for speech production, suggesting that babbling and early words are relatively immune to language-specific effects until the second year of life (Eilers et al. 1993).

At first glance, the absence of language-specific effects on early speech production looks like evidence in favor of Jakobson's classic proposal that speech development is governed by a universal markedness hierarchy (Jakobson 1968), with all children everywhere displaying the same passage from unmarked ("easy", universal) to marked ("hard", language-specific) speech contrasts. However, careful descriptive studies of early phonological development suggest instead that there are large individual differences among children (even within a single language) in the sounds that they prefer for babble and early words (Vihman 1986). Studies of the relationship between word com-prehension and phonological production in the first two years of life suggest that children may start with "favorite phonemes" that are at least partially derived from the sounds that are present in their first and favorite words (Leonard et al. 1980).

Word comprehension and production. A great deal has been learned in the last few years regarding cross-linguistic similarities and differences in early lexical development, due in part to the development and proliferation of new parent report instruments that are low in cost but high in reliability and validity (Fenson et al. 1994, in press). By tapping into parental knowledge, researchers have charted means and variations in word comprehension and production between 8-30 months of age, with instruments that are now available in more than a dozen languages (Afrikaans, American Sign Language, Catalan, Chinese, Croatian, Danish, Dutch, English [British], English [New Zealand], Finnish, French [Canadian], Greek, Hebrew, Icelandic, Italian, Japanese, Korean, Malawian, Polish, Sign Language of the Netherlands, Spanish [Mexican], Spanish [Spain], Swedish). These parental inventories rely on recognition memory rather than recall (using checklists of words that are among the first 600-700 to be acquired in that language), and they are used only within the age ranges in which parents can give reliable reports of newly emerging behaviors (e.g. word comprehension can only be assessed with these methods between 8-18 months; word production can be assessed reliably between 8-30 months). Briefly summarized, two universal conclusions have emerged from this multinational effort: (1) average onset times appear to be the same across languages for word comprehension (810 months) and word production (11-13 months); (2) huge variation in lexical growth is found in every language, and appears to be equivalent across languages in shape and magnitude (e.g. a range from no word 
production at all to production of more than 500 words at 24 months of age).

Although cross-language similarities outweigh differences in these studies, a few cross-language variations have emerged (Caselli et al. 1995, Caselli et al. 1999). For example, Italian children appear to have larger repertoires of social words (including proper nouns and social routines) than their American counterparts. These differences reflect cultural contrasts, including the fact that Italian infants tend to live in closer proximity to an extended family (e.g. on average, "grandma" is the 30th word produced in the U.S. norms but the 5 th word produced in the Italian norms). There are also small but significant differences in the order and shape of function word production between 16-30 months (slow and constant linear growth in Italian; a flat function followed by a nonlinear spurt in English), which may be related to structural contrasts between the two languages (including differences in the perceptual salience of grammatical function words).

A lively debate is currently underway regarding cross-linguistic differences in the order of emergence of nouns vs. verbs. In a classic paper, Gentner (1982) argued that nouns must always precede verbs in development, because early verbs refer to evanescent events while early nouns refer to solid and bounded objects, and because verbs tend to carve up reality in more variable ways from one language to another. This view has been challenged by Gopnik and Choi for Korean (1995) and by Tardif for Chinese (1996). Based primarily on analyses of free speech, these authors report that verbs are acquired early in these languages (often before nouns), because verbs are more salient: they appear in sentence-final position in Korean, an SOV language, and both languages permit extensive subject and object omission, so that a sentence is often composed of a single naked verb. Gopnik and Choi also suggested that these differences feed into nonlinguistic cognition, resulting in better performance by Korean children on means-end tasks (which are related to verbs) and better performance by English children on object permanence tasks (which are related to nouns). This interesting proposal has been challenged by studies using diaries and/or parental report (Pae 1993, for a review, see Caselli et al. 1999), and by studies in which novel verbs and nouns are taught to American and Korean children (Au et al. 1994). In those studies, the same familiar noun-before-verb pattern is observed in English, Italian, and Korean, despite sharp contrasts in linguistic structure and in the verb-noun ratios to which children are exposed. Caselli et al. (1999) suggest that free-speech records may yield differences because they are sensitive language-specific constructions that are high in frequency (i.e. what children like to do), while parent report yields a more representative estimate of the child's full lexical repertoire (i.e. what children know).
Choi and Bowerman (1991) have built on another difference between English and Korean: both languages have prepositions to convey the concepts "in" and "out", but Korean also makes a contrast between "inclose-fitting" and "in-loose-fitting". Young Korean children seem to pick this up quite easily, and show differential response to terms for containment and support by 18 months of age (McDonough et al. 1997). It may be that children are sensitive to "small-scale" contrasts in lexical frequency and salience that draw their attention to specific social and contextual facts (e.g. to grandmothers, or to the close fit between objects and containers), but these are not sufficient to move large-scale contrasts like the cognitive and linguistic factors that differentiate nouns from verbs.

Development of grammar. The most compelling evidence for cross-language variation begins between 18-20 months (on average), when grammatical development is finally underway. Ironically, early crosslinguistic work on language acquisition was based on the assumption that grammar (as opposed to phonology or the lexicon) would prove to be the bastion of language universals. Some secondary sources still claim that "all children acquire language on the same schedule, in the same way," and this putative fact has led to further claims about a "universal bioprogram" that governs language acquisition in children as well as the emergence of new languages from pidgin codes (i.e. creolization, Bickerton 1984). In this scenario, all children (and all creoles) begin their linguistic careers with single uninflected words, followed by telegraphic combinations of uninflected words in ordered strings, with inflections and function words acquired only after this syntactic base has been established. None of these proposed universals have held up in cross-linguistic research.

Grammatical development does begin with something like a one-word stage in every language, but there are cross-language variations in the form of one-word speech. For example, infant speakers of Western Greenlandic start out by producing little pieces of the large and complex words of their language (in which a sentence may consist of a single word with 10-12 inflections). In other richly inflected languages (e.g. Turkish), children often produce inflected nouns and verbs late in the one-word stage, before they have produced any word combinations at all. Some of these inflected forms may be accomplished by rote, but when there are multiple examples in which the same word appears with several contrasting inflections, it seems reasonable to infer that some kind of productive process is underway.

When word combinations are unequivocally established (between 20-24 months, on average), the evidence suggests that all children everywhere are trying to convey the same basic stock of meanings (e.g. possession, location, volition, disappearance and reappearance, and basic aspects of transitivity). Table 1 
illustrates some contrasting infant expressions in English and Italian for the same basic semantic relations, reported for every language studied to date. However, as Martin Braine was the first to report (Braine 1976), there are striking differences across languages in the linguistic forms that 2-year-olds use to convey these meanings. Word order is rigidly preserved in some languages (especially English), but it varies markedly in others (Bates 1976). English children produce a relatively high proportion of sentence subjects, compared with Italian children at the same stage (Valian 1991). Telegraphic speech is typical of some children, but even in English there are individual children who use a high ratio of pronouns and function words in their first word combinations (albeit with limited productivity-Bates et al. 1988). The entire system of case morphology appears to be mastered by Turkish children by 2 years of age, reflecting the exceptional regularity and phono-logical salience of Turkish inflections (Slobin 1985). Finally, many so-called complex forms appear quite early if they are very frequent and used for common pragmatic purposes (e.g. relative clauses in Italian, which are five times as common in Italian 3-year-olds than they are in their English counterparts-Bates \& Devescovi 1989, passives in Sesotho, used very fre-quenty by adults and acquired by 3 years of age by Sesotho children-Demuth 1989).

To some extent, this had to be true. For example, adult Italians have to produce approximately three times more morphological contrasts than English speakers to convey the same idea. This fact leaves us with at least two logical possibilities for early grammatical develop-ment: (1) Italian children will take three times as long to acquire their grammar, or (2) Italian and English children will acquire their respective languages at the same rate, but along the way Italian children will produce roughly three times as much morphology as their English counterparts. Evidence to date provides support for the latter view. In fact, if anything, children exposed to richly and systematically inflected languages may get off the ground faster, suggesting that the contrasting forms in their input force earlier learning of inflectional options-a result that has also been seen in connectionist simulations of grammatical learning (Harris 1991, MacWhinney \& Leinbach 1991).

In fact, grammatical errors are surprisingly rare in early child grammars (Slobin, 1985-1997), despite the many opportunities for error that are present in richly inflected languages. Tomasello $(1992,1998)$ has argued that this low incidence of error reflects a highly conservative approach to learning and generalization, a verb-by-verb and construction-by-construction approach in which undergeneralization (use of a new inflection or ordering principle with a small subset of legal options) is far more common than the oft-cited phenomenon of overgeneralization (use of a new inflec- tion outside of its domain). The theoretical literature on grammatical development has focused on over-generalization (e.g. overextension of the regular past tense, as in "goed" and "comed"), due in part to the belief (now under challenge) that such cases constitute evidence for the maturation of a rule system and/or the mastery of individual rules (compare Elman et al. 1996 and Juola \& Plunkett 1998 with Marcus 1999 and Pinker 1999). However, such cases are far less common that one might infer from the space that they occupy in textbooks (Maratsos 2000, Marcus et al. 1992), and it is no longer clear that they require a maturational or a rulebased account. To underscore the extraordinary richness, diversity and language specificity that is observed in the speech of 2-year-olds, a series of examples from Slobin and other sources is presented in Table 2.

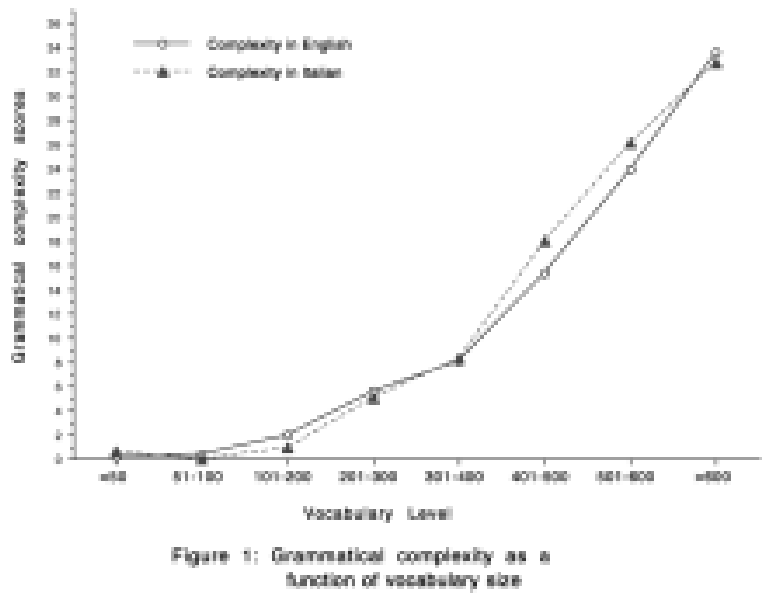

As a final point, recent evidence suggests that the single best predictor of early grammatical development comes from outside the grammar, with grammatical changes tied in both rate and shape to vocabulary expansion (Bates \& Goodman 1997, Marchman et al. 1991). Figure 1 (redrawn from Caselli et al. 1999) illustrates a powerful nonlinear relationship between vocabulary expansion and grammatical growth in large samples of English- and Italian-speaking children. These results are based on parental report, but they have been validated repeatedly against samples of free speech. Given large differences in the number of inflections that must be acquired by English and Italian children, these similarities are striking. However, they are based on instruments that were constructed to be comparable in numbers of vocabulary items (between 670-690) and grammatical items (37 pairs of sentence contrasts in each language, tapping into the structures that emerge for each language between 16-30 months). Hence they do not permit us to see rich cross-language differences in amount of morphology. We now have a large study in progress in which Italian and English children are matched for vocabulary size (from parental report), permitting us to compare free-speech samples together with parent reports of the three longest utterances that they have heard their children produce in 
the last two weeks. Evidence to date provides further support for a powerful link between grammatical development and vocabulary size in both languages, but it also unleashes the structural differences masked in Figure 1. Some examples of the sentences produced by a subset of Italian vs. English children at the same vocabulary level are presented in Table 3, which speaks for itself.

\section{Cross-linguistic variations in aphasia}

In contrast with child language and adult psycholinguistics (relatively modern fields that blossomed in the 1960's), the study of acquired speech and language disorders in adults (i.e. aphasia) has been underway for literally thousands of years (Goodglass 1993). However, the English language has dominated research on aphasia since World War II, with the establishment of VA Hospitals in conjunction with academic research centers, and the development of modern diagnostic batteries. Although considerable progress has been made, the hegemony of English in aphasia research has led to some historical errors that have only been corrected in the last few years, as a result of new crosslinguistic studies of grammatical and lexical symptoms.

The term "agrammatism" is attributable to Arnold Pick (1913/1973), whose own research was based on aphasic speakers of German and Czech. Pick clearly notes that there are two forms of agrammatism: nonfluent (associated with frontal damage) and fluent (associated with temporal-lobe damage). The frontal form is a symptom of Broca's aphasia, and is characterized by omissions and reductions in complexity, coupled with occasional errors of substitution. The temporal form is associated with Wernicke's aphasia, and "is characterized by erroneous grammatical constructions (paragrammatisms), in contrast to the frontal type with its telegraphic style" (Pick, p. 76). In other words, Broca's aphasics err by omission, Wernicke's aphasics err by substitution. In both cases, Pick believed that patients retain "Sprachgefuehl" or "feeling for language", a deep knowledge of their grammar despite these contrasting symptoms of grammatical expression. He notes, however, that the two forms of agrammatism might look very different in English, "An essentially formless language of high standing" (p. 80). Pick was prophetic: from the 1960's until today, based primarily on studies of English, receptive and expressive agrammatism have been identified primarily with Broca's aphasia, and by extension, grammatical processing has been ascribed to regions of left frontal cortex (Caplan \& Waters 1999a, b, Dick \& Bates in press, see papers in Kean 1985, Kim et al. 1997).

Detailed reviews of this historical anomaly are provided in Bates \& Goodman (1997), Bates \& Wulfeck (1989), and Bates et al. (1991b). The punchline is straightforward: the equation of grammatical deficits with damage to Broca's area derives from a peculiarity of English. Because English has relatively sparse gram-matical morphology, errors of substitution are difficult to detect, but errors of omission (especially omission of function words) are very evident. It is therefore easy to discount the severity of grammatical deficits in English-speaking Wernicke's aphasics, since their speech is otherwise relatively fluent, preserving melodic line, with function words included in appropriate positions. Consider an analogy: there is a genetic deficit that results in the inability to trill " $r$ 's"; this deficit is very apparent in Italian (where it is known to run in families), but entirely undetectable in English. Fluent paragrammatism has a similar status.

The equation of agrammatism with damage to Broca's area was supported by well-controlled studies of sentence comprehension in English-speaking patients that revealed deficits in the use of grammar by Broca's aphasics that are not evident in bedside conversations (Grodzinsky in press, Heilman \& Scholes 1976, Kean 1985, Zurif \& Caramazza 1976). Unfortunately, as Goodglass (1993) notes in his review of this literature, many of the original studies compared Broca's to elderly controls but did not investigate receptive agrammatism in other patient groups. More recently, specific deficits in the receptive processing of inflections, function words and complex syntax have been reported for virtually every form of aphasia, and for many other disorders as well (for reviews, see Bates \& Goodman 1997, Dick et al. 1999). Furthermore, these receptive deficits have also been demonstrated in normal college students forced to process sentence stimuli under perceptual degradation (Dick et al. 1999, Kilborn 1991) or cognitive overload (Blackwell \& Bates 1995, Miyake et al. 1994). Indeed, now that psycholinguistic techniques have been applied to a wide variety of patient groups, similarities in profiles of deficit greatly outweigh differences, a conclusion summarized as follows by Sheila Blumstein and William Milberg:

"What we have learned are two complementary findings: (1) that structural analyses reveal similar patterns of breakdown (qualitatively, if not quanti-tatively) across patients. In particular, those properties of language that are more "complex" are more vulnerable and a hierarchy of impairment can be established within each linguistic domain, and (2) that patients rarely have a selective impairment affecting only a single linguistic component. Most patients evidence a constellation of impairments implicating deficits that affect phonology, the lexicon, as well as syntax." (Blumstein \& Milberg 2000, p. 27).

Our own cross-linguistic results and those of other investigators are in accord with this conclusion (Bates et al. 1991b, Menn \& Obler 1990), but they add an extra dimension: the hierarchy of difficulty that patient groups share can vary over languages, and crosslinguistic studies can help us to develop a better theory of just what "hard" and "easy" means. At the same time, cross-linguistic studies also reveal just how much detailed language-specific knowledge ("Sprachgefuehl") is retained by aphasic patients, despite their 
lexical and grammatical errors, forcing a rethinking of aphasic syndromes in terms of processing deficits rather than loss of linguistic content. This conclusion is supported by studies of sentence comprehension, production and grammaticality judgment, all showing significant differences between patient groups that correspond directly to cross-linguistic differences in normals. Across studies of both comprehension and production, both Broca's and Wernicke's aphasics retain the basic word order biases of their native language (e.g. SVO in English, Italian, German; SOV in Turkish and Japanese; both SVO and SOV in Hungarian, depending on definiteness of the object). In the same studies, use of grammatical morphology proves to be especially vulnerable in receptive processing, but the degree of loss is directly correlated with strength of morphology in the premorbid language. In studies of grammaticality judgment, fluent and nonfluent patients show above-chance abilities (at equivalent levels) to detect subtle grammatical errors, often in constructions that they themselves can no longer produce without error (Devescovi et al. 1997 for Italian, Linebarger et al. 1983, Lu et al. in press for Chinese, Shankweiler et al. 1989 for Serbo-Croatian, Wulfeck 1988).

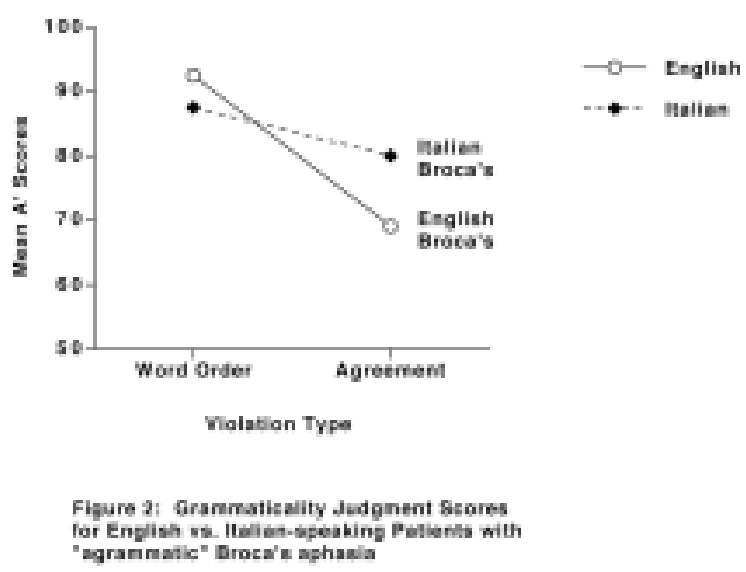

Because of length limitations, we will use only one concrete empirical example to illustrate this very general point. Figure 2 (redrawn from Wulfeck et al. 1991) compares A' scores (a nonparametric variant of d', correcting for response bias) in Italian and American Broca's aphasics in a grammaticality judgment task. Patients were asked to push one of two buttons to indicate whether a sentence was "bad" (has a mistake) or "good" (has no mistakes). Two types of errors were derived from the same well-formed sentence materials: word order errors (e.g. "The girl is selling books..." became "The girl selling is books...") and agreement errors (e.g. "The girl are selling books...."). Figure 2 displays a significant language by patient group interaction, and illustrates three conclusions: (1) agrammatic Broca's aphasics are above chance in their judgments of grammaticality in both languages (although they do perform below normal controls); (2) for both groups, agreement errors are harder to detect than word order errors (also true for normals under cognitive overload - Blackwell \& Bates 1995); (3) however, Italian Broca's are significantly better at detecting agreement errors than their American counterparts, while Americans are significantly better at detecting word order errors. We also looked at reaction time data for the same patients compared with college-age controls, using $\mathrm{z}$-scores to equate for the overall difference in RTs between groups. This analysis showed that Broca's aphasics also retain the characteristic RT profile for their language: Italians are faster at detecting agreement errors, Americans are faster at detecting word order errors.

The general picture that has emerged so far is one in which cross-language differences are robust under brain damage, but patient group differences are few and far between. This does not hold, however, for all linguistic symptoms. For example, the fluency differences that distinguish Broca's and Wernicke's aphasics are attested in every language, although the omissionbased profile of Broca's and the substitution-based profile of Wernicke's take different forms depending on the opportunities presented by the language. There are also some very puzzling differences in lexical access that show up in every language tested to date, including a peculiar double dissociation between nouns (better preserved in Broca's aphasics) and verbs (better preserved in Wernicke's aphasics). This dissociation has now been reported in English (Goodglass 1993), Italian (Miceli et al. 1984), Hungarian (Osmán-Sági 1987) and Chinese (Bates et al. 1991a, Bates et al. 1993, Chen \& Bates 1998). The Chinese version of this dissociation is particularly interesting, for two reasons: (1) it demonstrates that the verb-finding difficulty of Broca's aphasics cannot be attributed to the heavy morphological load that verbs bear in Indo-European languages, because verbs (like nouns) are uninflected in Chinese; (2) it occurs at the whole-word level (regardless of sublexical structure), but it also occurs at the sublexical level in compound words (e.g. given a VN verb like "da-tie", literally "strike-iron", Broca's have more difficulty lexicalizing the verb element "da-", while Wernicke"s have more trouble with the nominal element "-tie"). Hence the noun-verb dissociation is not a by-product of grammatical processing, nor is it a simple product of two separate lexicons (verbs in the front, nouns in the back). Instead, the processes responsible for this double dissociation must be tied to the meanings (lexical and sublexical) that underlie nouns vs. verbs (Damasio \& Tranel 1993, Perani et al. 1999). These results illustrate the value of the second crosslinguistic strategy described earlier, where the special opportunities offered by a given language are exploited to learn more about the nature of (in this case) wordfinding deficits in aphasia. 


\section{Cross-linguistic variations in word and sentence processing}

This will be the shortest section in our review, because cross-linguistic studies of word and sentence processing in normal adults are relatively rare, compared with the rich comparative data base that is now available for child language and adult aphasia. In surveying several major textbooks in psycholinguistics (which we will not cite), one finds many statements about "the speaker" or "the listener" in reference to studies that were carried out almost exclusively in English. In none of these textbooks have we been able to find any mention of the possibility that results might look a bit different in another language. At the sentence level, some exceptions to this general trend include Cuetos \& Mitchell (1988), Cuetos et al. (1996), Hillert (1998), MacWhinney \& Bates (1989), and Thornton et al. (1998). In addition, there has been a marked increase in research on aspects of inflectional and derivational morphology that are underrepresented in English (Friederici et al. 1999, Sandra \& Taft 1994). Although these trends are promising, few other basic works in adult psycholinguists take into account the problem of gen-eralizing from English-specific results to universal mechanisms.

One of the largest bodies of comparative research on sentence comprehension and production can be found in MacWhinney \& Bates (1989), with chapters on the hierarchy of cues to sentence processing displayed by native speakers of English, Italian, German, Spanish, French, Dutch, Hebrew, Hungarian, SerboCroatian, Turkish, Chinese, Japanese, and Warlpiri. Table 4 (from Bates \& MacWhinney 1989, Table 1.1) summarizes the order of importance of cues to actor assignment across all these languages, in adults and (where available) in children. All of these studies rely on a single method: a "Who did it?" task in which listeners are presented (on-line or off-line) with some factorial combination of word order (Noun-Verb-Noun; Noun-Noun-Verb; Verb-Noun-Noun), morphology (agreement or case marking on the first noun, second noun, or both), semantics (animate-animate; animateinanimate; inanimate-animate), contrastive stress (on the first noun, second noun, or neither) and/or topicalization. The factorial design permits an assessment of cue strength (a correlate of cue validity), by determining which cues "win" (and to what extent) in various competing and converging combinations of information. The cue hierarchies in Table 4 reflect the "winners" in a competition design. For example, given a sentence like "The rock is kissing the cow", English listeners (from ages 2 to 92) choose the first noun (slavishly following SVO) while speakers of most other languages choose the second noun (animacy defeats basic word order). Given another sentence like "The cows is chasing the horse", English listeners also choose the first noun (SVO defeats agreement), while speakers of more richly inflected languages tend to choose the second noun (agreement trumps canonical word order). These "victories" and "defeats" are not absolute, within or across subjects; they are probabilistic in nature, directly corresponding to levels of cue validity within each language.

In some languages, this competition design results in a mix of grammatical and ungrammatical sentences, a fact that has led some critics (Gibson 1992) to conclude that results cannot be generalized to normal language processing. However, the same probabilistic results have been observed in languages in which all combinations are grammatical, and similar results are obtained in Hungarian when semigrammatical forms are allowed (using common nouns) or disallowed (using possessive markers like "Your red one is chasing my blue one", which do not carry case). For these reasons, MacWhinney and Bates conclude that it is possible to derive generalizable principles from stimuli that include semigrammatical forms (similar to the visual illusions used by perceptual psychologists to obtain insight into the principles that govern visual perception). However, these results do not respond to another criticism of this cross-linguistic design: results for simple sentences may reflect heuristics or "shortcuts" that do not generalize to processing of more complex sentence forms.

To investigate this last possibility, Bates, Devescovi and D'Amico (1999) examined sentence comprehension in English and Italian, comparing reliance on word order vs. agreement in complex two-clause sentences. All sentences contained three noun participants, with one "criminal verb" and one "verb of witness" either in the main clause or the relative clause (e.g. "The secretaries who the journalist sees shoot the cowboy"; "The waitress hears the policeman who the ballerinas stab."). Subjects were asked to "identify the one who does the bad action, as fast as you can" so that we could direct the subject's attention either to the main or relative clause, within random lists varying word order and agreement conditions at both levels of the sentence. Sentences were presented visually, and reading times were recorded up to a button press, at which point subjects reported orally (off-line) the name of the 'criminal'. We found the same massive cross-language differences uncovered in previous studies: overwhelming reliance on word order in English, in both the main clause and the relative clause; overwhelming reliance on agreement in Italian, at both levels of the sentence. We also uncovered new information about the costs associated with these contrasting strategies. First, RTs were more affected by center embedding in English than Italian, suggesting that the reaction time costs associated with center embedding are greater with a strong reliance on word order. Second, RTs were slower for morphologically ambiguous sentences in Italian but not in English, suggesting that Italian subjects are frustrated by the absence of their favorite cue. These differences in processing costs may reflect a 
fundamental contrast between "geometric strategies" (track word order) and "algebraic strategies" (match agreement endings), with implications for the profiles of vulnerability observed in each language for complex sentences, in aphasic patients and in normals under stress.

Cross-linguistic studies within the Competition Model constitute one of the largest and oldest research programs using language differences as a betweensubjects variable. However, there is a growing body of cross-language research from other points of view as well. For example, studies based on English had led some investigators to conclude that listeners have universal parsing biases (e.g. Minimal Attachment, Late Closure) that lead them to prefer one interpretation of ambiguous phrases over another, sometimes resulting in garden path phenomena. Thus, given a phrase like "The daughter of the colonel who had the accident," English listeners typically conclude that the accident happened to the colonel, which means that they prefer to attach the relative clause to the nearest (local) noun phrase. However, Cuetos and Mitchell (1998) showed that Spanish listeners have a different bias, preferring a reading in which the accident happened to the daughter, which means that they prefer to attach the relative clause to the highest noun phrase. This pioneering study set off a flurry of cross-language studies investigating putative universal constraints on sentence processing, resulting in the general conclusion that listeners behave as they should, with processing biases that are appropriate for the structural options and statistical distributions in their language (Mitchell \& Brysbaert 1998, Thornton et al. 1998; but see Frazier \& Clifton 1987).

Other recent studies have focused on grammatical cues to lexical access, including phenomena like grammatical gender agreement or noun classifiers that simply are not available in English. Significant gender and/or classifier priming has now been reported for Serbo-Croatian (Gurjanov et al. 1985), French (Grosjean et al. 1994), Italian (Bates et al. 1996), German (Hillert \& Bates 1996, Jacobsen 1999), Russian (Akhutina et al. 1999), Chinese (Lu et al. in press) and Swahili (Alcock \& Ngorosho 2000). In most of these studies, results include facilitation relative to neutral baseline, indicating the presence of automatic, "topdown" effects (but see Friederici \& Jacobsen 1999 for a different view). In addition, studies of Spanish (Wicha et al. submitted) and Italian (Bentrovato et al. 1999) have shown that grammatical gender interacts significantly with sentential meaning when pictures are named within a sentence context, with the two sources of information together producing massive facilitation (around $100 \mathrm{~ms}$ ) relative to several different neutral baselines. The emerging picture is one in which language-specific cues to lexical access are used as soon as they are available, alone or in combination with other sources of information. In this respect, language pro- cessing is similar to many other complex perceptualmotor skills, suggesting that language use follows domain-general principles.

\section{Conclusion}

The dominance of English in 20th-century psycholinguistics was a historical accident, more socio-political than scientific. However, it has had particularly unfortunate consequences for those fields that try to study the universal psychological and neural underpinnings of language. Psycholinguistics has finally broken away from the hegemony of English, and the field is better for it. There is, however, an immense amount of work that needs to be done, to verify whether English-based findings can be generalized, and to explore the opportunities afforded by the dramatic structural contrasts that characterize human language.

\section{REFERENCES}

Akhutina, T., Kurgansky, A., Polinsky, M., \& Bates, E. (1999). Processing of grammatical gender in a three-gender system: Experimental evidence from Russian. Journal of Psycholinguistic Research, 28(6), 695-713.

Alcock, K.J., \& Ngorosho, D (2000). Grammatical noun class agreement processing in Kiswahili (Tech. Rep. CRL-0003). La Jolla: University of California, San Diego, Center for Research in Language.

Aslin, R.N., Jusczyk, P.W., \& Pisoni, D.B. (1998). Speech and auditory processing during infancy: Constraints on and precursors to language. In W. Damon (Series Ed.) \& D. Kuhn \& R. Siegler (Vol. Eds.), Handbook of child psychology: Vol. 2. Cognition, perception \& language (5th ed., pp. 147-198). New York: Wiley.

Au, T., Dapretto, M., \& Song, Y.-K. (1994). Input vs. constraints: Early word acquisition in Korean and English. Journal of Memory and Language, 33(5), 567-582.

Bates, E. (1976). Language and context: Studies in the acquisition of pragmatics. New York: Academic Press.

Bates, E., Bretherton, I., \& Snyder, L. (1988). From first words to grammar: Individual differences and dissociable mechanisms. New York: Cambridge University Press.

Bates, E., Chen, S., \& Tzeng, O., Li, P., \& Opie, M. (1991a). The noun-verb problem in Chinese aphasia. Brain and Language, 41, 203-233.

Bates, E., Chen, S., Li, P., Opie, M., \& Tzeng, O. (1993). Where is the boundary between compounds and phrases in Chinese? A reply to Zhou et al. Brain and Language, 45, 94-107.

Bates, E., \& Devescovi, A. (1989). Crosslinguistic studies of sentence production. In B. MacWhinney \& E. Bates (Eds.), The crosslinguistic study of sentence processing (pp. 225-253). New York: Cambridge University Press. 
Bates, E., Devescovi, A., \& D’Amico, S. (1999). Processing complex sentences: A cross-linguistic study. Language and Cognitive Processes, 14(1), 69-123.

Bates, E., Devescovi, A., Hernandez, A., \& Pizzamiglio, L. (1996). Gender priming in Italian. Perception \& Psychophysics, 85(7), 992-1004.

Bates, E., \& Elman, J. (1996). Learning rediscovered. Science, 274, 1849-1850.

Bates, E., \& Goodman, J. (1997). On the inseparability of grammar and the lexicon: Evidence from acquisition, aphasia and real-time processing. In G. Altmann (Ed.), Special issue on the lexicon, Language and Cognitive Processes, 12(5/6), 507586.

Bates, E., \& MacWhinney, B. (1989). Functionalism and the competition model. In B. MacWhinney \& E. Bates (Eds.), The crosslinguistic study of sentence processing (pp. 3-76). New York: Cambridge University Press.

Bates, E., \& Wulfeck, B. (1989). Crosslinguistic studies of aphasia. In B. MacWhinney \& E. Bates (Eds.), The crosslinguistic study of sentence processing (pp. 328-374). New York: Cambridge University Press.

Bates, E., Wulfeck, B., \& MacWhinney, B. (1991b). Crosslinguistic research in aphasia: An overview. Brain and Language, 41, 123-148.

Bentrovato, S., Devescovi, A., D’Amico, S., \& Bates, E. (1999). The effect of grammatical gender and semantic context on lexical access in Italian. Journal of Psycholinguistic Research, 28(6), 677693.

Berman, R.A., \& Slobin, D.I. (1994). Relating events in narrative: A cross-linguistic developmental study [in collaboration with Ayhan Aksu-Koc et al.]. Hillsdale, NJ: Erlbaum.

Bickerton, D. (1984). The language bioprogram hypothesis. Behavioral and Brain Sciences, 7, 173-187.

Blackwell, A., \& Bates, E. (1995). Inducing agrammatic profiles in normals: Evidence for the selective vulnerability of morphology under cognitive resource limitation. Journal of Cognitive Neuroscience, 7(2), 228-257.

Blumstein, S.E., \& Milberg, W.P. (2000). Neural systems and language processing: Toward a synthetic approach. Brain and Language, 71(1), 26-29.

Bowerman, M., \& Choi, S. (1994, January). Linguistic and nonlinguistic determinants of spatial semantic development: A crosslinguistic study of English, Korean, and Dutch. Paper presented at Boston University Conference on Language Development.

Boysson-Bardies, B., Sagart, L., \& Durand, C. (1984). Discernible differences in the babbling of infants according to target language. Journal of Child Language, 11, 1-15.
Braine, M.D.S. (1976). Children's first word combinations. With commentary by Melissa Bowerman. Monographs of the Society for Research in Child Development, 41(Serial No. 164).

Caplan, D., \& Waters, G. (1999a). Issues regarding gen-eral and domain-specific resources. Behavioral and Brain Sciences, 22(1), 114-126.

Caplan, D, \& Waters, G.S. (1999b). Verbal working memory and sentence comprehension. Behavioral and Brain Sciences, 22(1), 77-94, 122-126.

Caselli, M.C., Bates, E., Casadio, P., Fenson, J., Fenson, L., Sanderl, L., \& Weir, J. (1995). A cross-linguistic study of early lexical development. Cognitive Development, 10, 159-199.

Caselli, M.C., Casadio, P., \& Bates, E. (1999). A comparison of the transition from first words to grammar in English and Italian. Journal of Child Language, 26, 69-111.

Chen, H.-C., \& Tzeng, O. (Eds.). (1992). Language processing in Chinese. Amsterdam: NorthHolland.

Chen, H.-C., \& Zhou, X., (Eds.). (1999). Special issue: Processing East Asian languages. Language and Cognitive Processes, 14(5/6), 425-748.

Chen, S., \& Bates, E. (1998). The dissociation between nouns and verbs in Broca's and Wernicke's aphasia: Findings from Chinese. Special issue on Chinese aphasia, Aphasiology, 12(1), 5-36.

Choi, S., \& Bowerman, M. (1991). Learning to express motion events in English and Korean: The influence of language-specific lexicalization patterns. Cognition, 4l(1-3), 83-121.

Coltheart, M., Patterson, K.E., \& Marshall, J.C. (1980). Deep dyslexia. London: Routledge \& Keagan Paul.

Cuetos, F., \& Mitchell, D.C. (1988). Cross-linguistic differences in parsing: Restrictions on the use of the Late Closure Strategy in Spanish. Cognition, 30, 73-105.

Cuetos, F., Mitchell, D.C., \& Corley, M.M.B. (1996). Parsing in different languages. In M. Carreiras, J. Garcia-Albea, \& N. Sebastian-Galles (Eds.), Language processing in Spanish (pp. 145-187). Mahwah, NJ: Lawrence Erlbaum.

Cutler, A., \& Chen, H.-C. (1997). Lexical tone in Cantonese spoken-word processing. Perception \& Psychophysics, 59, 265-279.

Damasio, A., \& Tranel, D. (1993). Nouns and verbs are retrieved with differently distributed neural systems. Proceedings of the National Academy of Sciences, USA, 90, 4957-4960.

Demuth, K. (1989). Subject, topic and Sesotho passive. Journal of Child Language, 17, 67-84.

Devescovi, A., Bates, E., D’Amico, S., Hernandez, A., Marangolo, P., Pizzamiglio, L., \& Razzano, C. (1997). An on-line study of grammaticality judgments in normal and aphasic speakers of Italian. In 
L. Menn (Ed.), Special issue on cross-linguistic aphasia. Aphasiology, 11(6), 543-579.

Devescovi, A., D'Amico, S., Smith, S., Mimica, I., \& Bates, E. (1998). The development of sentence comprehension in Italian and Serbo-Croatian: Local versus distributed cues. In B.D. Joseph \& C. Pollard (Series Eds.), \& D. Hillert (Vol. Ed.), Syntax and semantics: Vol. 31. Sentence processing: A cross-linguistic perspective (pp. 345-377). San Diego: Academic Press.

Dick, F., \& Bates, E. (in press). Grodzinsky's Latest Stand - or, just how specific are "lesion-specific" deficits? Behavioral and Brain Sciences.

Dick, E., Bates, E., Wulfeck, B., Utman, J., \& Dronkers, N. (1999). Language deficits, localization, and grammar: Evidence for a distributive model of language breakdown in aphasics and normals (Tech. Rep. No. 9906). La Jolla: University of California, San Diego, Center for Research in Language.

Eilers, R., Oller, D.K. Levine, S., Basinger, O., Lynch, M., \& Urbano, R. (1993). The role of prematurity and socioeconomic status in the onset of canonical babbling in infants. Infant Behavior and Development, 16, 297-316.

Elman, J., \& Bates, E. (1997). Acquiring language: Response. Science (Letters) 276, 1180.

Elman, J., Bates, E., Johnson, M., Karmiloff-Smith, A., Parisi, D., \& Plunkett, K. (1996). Rethinking innateness: A connectionist perspective on develop-ment. Cambridge, MA: MIT Press/ Bradford Books.

Fenson, L., Dale, P.A., Reznick, J.S., Bates, E., Thal, D., \& Pethick, S.J. (1994). Variability in early communicative development. Monographs of the Society for Research in Child Development, Serial No. 242, Vol. 59, No. 5.

Fenson, L., Bates, E., Dale, P., Goodman, J., Reznick, J.S., \& Thal, D. (in press). Measuring variability in early child language: Don't shoot the messenger. Comment on Feldman et al. Child Development.

Frazier, L., \& Clifton, C. (1996). Construal. Cambridge, MA: MIT Press.

Friederici, A.D., Garrett, M.F., \& Jacobsen, T. (Eds.). (1999). Special Issue: Processing grammatical gender. Journal of Psycholinguistic Research, $28(5,6)$.

Friederici, A.D., \& Jacobsen, T. (1999). Processing grammatical gender during language comprehension. Journal of Psycholinguistic Research, 28(5), 467-514.

Gentner, D. (1982). Why are nouns learned before verbs: Linguistic relativity versus natural partitioning. In S.A. Kuczaj II (Ed.), Language development, Vol. 2: Language, thought and culture. Hillsdale, NJ: Erlbaum.
Gibson, E. (1992). On the adequacy of the competition model. [Review of The crosslinguistic study of sentence processing]. Language, 68(4), 812-830.

Goodglass, H. (1993). Understanding aphasia. San Diego: Academic Press.

Gopnik, A., \& Choi, S. (1995). Names, relational words, and cognitive development in English- and Korean-speakers: Nouns are not always learned before verbs. In M. Tomasello \& W. Merriman, W. (Eds.), Beyond names for things: Young children's acquisition of verbs (pp. 63-80). Hillsdale, NJ: Lawrence Erlbaum.

Grodzinsky, Y. (in press). The neurology of syntax: Language use without Broca's area. Behavioral and Brain Sciences.

Grosjean, F., Dommergues, J-Y., Cornu, E., Guillelmon, D., \& Besson, C. (1994). The gender-marking effect in spoken word recognition. Perception \& Psychophysics, 56(5), 590-598.

Gurjanov, M., Lukatela, G., Lukatela, K., Savic, M., \& Turvey, M. (1985). Grammatical priming of inflected nouns by the gender of possessive adjectives. Journal of Experimental Psychology: Learning, Memory, and Cognition, 11(4), 692-701.

Haith, M.M. (1994). Visual expectations as the first step toward the development of future-oriented processes. In M.M. Haith, J.B. Benson, R.J. Rogers, Jr., \& B.F. Pennington (Eds.), The develop-ment of future-oriented processes (pp. 1138). Chicago: The University of Chicago Press.

Harris, C.L. (1991). Parallel distributed processing models and metaphors for language and development. Doctoral dissertation, University of California, San Diego.

Heilman, K.M., \& Scholes, R.J. (1976). The nature of comprehension errors in Broca's, conduction and Wernicke's aphasics. Cortex, 12, 258-265.

Hillert, D. (Ed.). (1998). Sentence processing: A crosslinguistic perspective. San Diego: Academic Press.

Hillert, D., \& Bates, E. (1996). Morphological constraints on lexical access: Gender priming in German. (Tech. Rep. No. 9601). La Jolla: University of California, San Diego, Center for Research in Language.

Hinton, G.E., \& Shallice, T. (1991). Lesioning an attractor network: Investigations of acquired dyslexia. Psychological Review, 98(1), 74-95.

Jacobsen, T. (1999). Effects of grammatical gender on picture and word naming: Evidence from German. Journal of Psycholinguistic Research, 28(5), 499514.

Jakobson, R. (1968). Child language. Aphasia and phonological universals. The Hague; Paris: Mouton.

Joanisse, M.F., \& Seidenberg, M.S. (1999). Impairments in verb morphology after brain injury: A connectionist model. Proceedings of the National Academy of Sciences USA, 96(13), 7592-7597. 
Juola, P., \& Plunkett, K. (1998). Why double dissociations don't mean much. In M.A. Gerns-bacher \& S. J. Derry (Eds.), Proceedings of the Twentiety Annual Conference of the Cognitive Science Society (pp. 561-566). Mahwah, NJ.: Erlbaum.

Jusczyk, P.W. (1997). Finding and remembering words: Some beginnings by English-learning infants. Current Directions in Psychological Science, 6(6), 170-174.

Jusczyk, P.W., Friederici, A.D., Wessels, J.M.I., Svenkerud, V., \& Jusczyk, A.M. (1993). Infants' sensitivity to the sound pattern of native-language words. Journal of Memory and Language, 32, 402-420.

Kean, M.-L. (Ed.).(1985). Agrammatism. Orlando: Academic Press.

Kilborn, K. (1991). Selective impairment of grammatical morphology due to induced stress in normal listeners: Implications for aphasia. Brain and Language, 41, 275-288.

Kim, K.H.S., Relkin, N.R., Lee, K.Y.-M., \& Hirsch, J. (1997). Distinct cortical areas associated with native and second languages. Nature, 388(6638), 171-174.

Kuhl, P.K. (1994). Learning and representation in speech and language. Current Opinion in Neurobiology, 4, 812-822.

Kuhl, P.K. (1985). Categorization of speech by infants. In J. Mehler \& R. Fox (Eds.), Neonate cognition: Beyond the blooming buzzing confusion. Hillsdale, NJ: Erlbaum.

Kuhl, P.K., Williams, K.A., Lacerda, F., Stevens, K.N., \& Lindblom, B. (1992). Linguistic experiences alter phonetic perception in infants by 6 months of age. Science, 255, 606-608.

Leonard, L.B., Newhoff, M., \& Mesulam, L. (1980). Individual differences in early child phonology. Applied Psycholinguistics, 1, 7-30.

Linebarger, M., Schwartz, M., \& Saffran, E. (1983). Sensitivity to grammatical structure in so-called agrammatic aphasics. Cognition, 13, 361-392.

Lu, C.-C., Bates, E., Li, P., Tzeng, O., Hung, D., Tsai, C.-H., Lee, S.-E., \& Chung, Y.-M. (in press). Judgments of grammaticality in aphasia: The special case of Chinese. Aphasiology.

MacWhinney, B. (1987). The competition model. In B. MacWhinney (Ed.), Mechanisms of language acquisition (pp. 249-308). Hillsdale, NJ: Erlbaum.

MacWhinney, B., \& Bates, E. (Eds.) (1989). The crosslinguistic study of sentence processing. New York: Cambridge University Press.

MacWhinney, B., Leinbach, J. (1991). Implementations are not conceptualizations -- Revising the verb-learning model. Cognition, 40(1), 121-157.

Maratsos, M. (2000). More overregularizations after all: New data and discussion on Marcus, Pinker, Ullman, Hollander, Rosen \& Xu. Journal of Child Language, 27(1), 183-212.
Marchman, V. (1993). Constraints on plasticity in a connectionist model of the English past tense. Journal of Cognitive Neuroscience, 5(2), 215-234.

Marchman, V., Bates, E., Burkhardt, A., \& Good, A. (1991). Functional constraints on the acquisition of the passive: Toward a model of the competence to perform. First Language, 11, 65-92.

Marcus, G. (1999). Do infants learn grammar with algebra or statistics? Response. Science, 284, 637.

Marcus, G., Pinker, S., Ullman, M., Hollander, M., Rosen, T.J., \& Xu, F. (1992). Overregularization in language acquisition. Monographs of the Society for Research in Child Development, 57.

Marcus, G., Vijayan, S., Rao, S.B., \& Vishton, P.M. (1999). Rule learning by seven-month-old infants. Science, 283(5398), 77-80.

McClelland, M., \& Seidenberg, M. (1989). A distributed developmental model of visual word recognition and naming. Psychological Review, 98, 523-568.

McClelland, J.L., Thomas, A.G., McCandliss, B.D., \& Fiez, J.A. (1999). Understanding failures of learning: Hebbian learning, competition for representational space, and some preliminary experimental data. In J.A. Reggia, E. Ruppin, \& D. Glanzman (Eds.), Progress in brain research, Vol. 121. Amsterdam: Elsevier.

McDonough, L., Choi, S., Bowerman, M., \& Mandler, J.M. (1997). The use of preferential looking as a measure of semantic development. In E.L. Bavin \& D. Burnham, Advances in infancy research. Norwood, NJ: Ablex Publishing.

Mehler, J., Jusczyk, P.W., Lambertz, G., Halsted, N., Bertoncini, J., \& Amiel-Tison, C. (1988). A precursor of language acquisition in young infants. Cognition, 29, 143-178.

Menn, L., \& Obler, L.K. (Eds.). (1990). Agrammatic aphasia: Cross-language narrative sourcebook. Amsterdam/Philadelphia: John Benjamins.

Miceli, G., Silveri, M., Villa, G., \& Caramazza, A. (1984). On the basis for the agrammatic's difficulty in producing main verbs. Cortex, 20, 207220.

Mitchell, D., \& Brysbaert, M. (1998). Challenges to recent theories of language differences in parsing: Evidence from Dutch. In B.D. Joseph \& C. Pollard (Series Eds.) \& D. Hillert (Vol. Ed.), Syntax and semantics: Vol. 31. Sentence processing: A crosslinguistic perspective (pp. 313-336). San Diego: Academic Press.

Miyake, A., Carpenter, P.A., \& Just, M.A. (1994). A capacity approach to syntactic comprehension disorders: Making normal adults perform like aphasic patients. Cognitive Neuropsychology, 11(6), 671717.

Orsolini, M., \& Marslen-Wilson, M. (1997). Universals in morphological representation: Evidence from 
Italian. Language and Cognitive Processes, 12, 147.

Osmán-Sági, J. (1987, August). Action naming in Hungarian aphasic patients. Abstracts of the Second World Congress of Neuroscience IBRO. Neuroscience, Supplement to Vol. 22, p. S509.

Pae, S. (1993). Early vocabulary in Korean: Are nouns easier to learn than verbs? Unpublished doctoral dissertation, University of Kansas.

Perani, D., Cappa, S., Schnur, T., Tettamanti, M., Collina, S., Rosa, M., \& Fazio, F. (1999). The neural correlates of verb and noun processing: A PET study. Brain, 122, 2337-2344.

Pick, A. (1973). Aphasia. (J. Brown, Ed. \& Trans.) Springfield, IL: Charles C. Thomas. (Original work published 1913).

Pinker, S. (1991). Rules of language. Science, 253, 530-535.

Pinker, S. (1999). Words and rules: The ingredients of language. New York: Basic Books.

Plaut, D., McClelland, J., Seidenberg, M., \& Patterson, K. (1996). Understanding normal and impaired word reading: Computational principles in quasiregular domains. Psychological Review, 103(1), 56-115.

Polka, L., \& Werker, J.F. (1994). Developmental changes in perception of nonnative vowel contrasts. Journal of Experimental Psychology: Human Per-ception and Performance, 20(2), 421435.

Rumelhart D., \& McClelland J.L. (Eds.). (1986). Parallel distributed processing: Explorations in the microstructure of cognition. Vol. 1. Foundations. Cambridge, MA: MIT Press.

Saffran, E.M., Aslin, R.N., \& Newport, E.L. (1996). Statistical learning by 8 -month-old infants. Science, 274, 1926-1928.

Saffran, J.R., Aslin, R.N., \& Newport, E.L. (1997, May). Acquiring language [Letter to the editor]. Science, 276 (5316), pp. 1180 , cont. on p.1276.

Sandra, D., \& Taft, M. (1994). Special issue: Morphological structure, lexical representation and lexical access. Language and Cognitive Processes, 9(3).

Say, T., \& Clahsen, H. (1999). Words, rules and stems in the Italian mental lexicon. Essex Research Reports in Linguistics, University of Essex.

Shankweiler, D., Crain, S., Gorrell, P., \& Tuller, B. (1989). Reception of language in Broca's aphasia. Language and Cognitive Processes, 4(1), 1-33.

Slobin, D. (1985). Crosslinguistic evidence for the language-making capacity. In D. Slobin (Ed.), The crosslinguistic study of language acquisition (Vol. 2, pp. 1157-1256). Hillsdale, NJ: Erlbaum.

Slobin, D. (Ed.). (1985-1997). The crosslinguistic study of language acquisition (Vols. 1-5). Hillsdale, NJ: Erlbaum.

Slobin, D. (1996). Two ways to travel: Verbs of motion in English and Spanish. In M. Shibatani
\& S.A. Thompson (Eds.), Grammatical constructions: Their form and meaning (pp. 195219). Oxford: Oxford University Press

Slobin, D., \& Bever, T.G. (1982). Children use canonical sentence schemas: A crosslinguistic study of word order and inflections. Cognition, 58, 265289.

Sokolov, J., \& Snow, C. (Eds.). (1994). Handbook of research in language development using CHILDES. Hillsdale, NJ: Erlbaum.

Tardif, T. (1996). Nouns are not always learned before verbs: Evidence from Mandarin speakers' early vocabularies. Developmental Psychology, 32(3), 492-504.

Thornton, R., Gil, M., \& MacDonald, M.C. (1998). Accounting for crosslinguistic variation: A constraint-based perspective. In B.D. Joseph \& C. Pollard (Series Eds.), \& D. Hillert (Vol. Ed.), Syntax and semantics: Vol. 31. Sentence processing: A cross-linguistic perspective (pp. 211-225). San Diego: Academic Press.

Tomasello, M. (1992). First verbs: A case study of early grammatical development. Cambridge [UK]; New York: Cambridge University Press.

Tomasello, M. (1998). The return of constructions. [Review of the book Constructions: A construction grammar approach to argument Structure]. J.ournal of Child Language, 25, 431-442.

Ullman, M., Corkin, S., Coppola, M., Hickok, G., Growdon, J.H., Koroshetz, W.J., \& Pinker, S. (1997). A neural dissociation within language: Evidence that the mental dictionary is part of declarative memory, and that grammatical rules are processed by the procedural system. Journal of Cognitive Neuroscience, 9(2), 266-276.

Valian, V. (1991). Syntactic subjects in the early speech of American and Italian children. Cognition, 40(1-2), 21-81.

Vihman, M. (1986). Individual differences in babbling and early speech: Predicting to age three. In B. Lindblom \& R. Zetterstrom (Eds.), Precursors of early speech. Basingstoke, Hampshire: MacMillan.

Werker, J., \& Tees, R. (1984). Cross-language speech perception: Evidence for perceptual reorganization during the first year of life. Infant Behavior and Development, 7, 49-63.

Wicha, N., Bates, E., Hernandez, A., Reyes, I., \& Gavaldón de Barreto (submitted). When zebras become painted donkeys: Interplay between gender and semantic priming in a Spanish sentence context.

Wulfeck, B. (1988). Grammaticality judgments and sentence comprehension in agrammatic aphasia. Journal of Speech and Hearing Research, 31, 7281.

Wulfeck, B., Bates, E., \& Capasso, R. (1991). A crosslinguistic study of grammaticality judgments 
in Broca's aphasia. Brain and Language, 41, 311336.

Zhou, X., Ostrin, R.K., \& Tyler, L.K. (1993). The noun-verb problem and Chinese aphasia: Comments on Bates et al. (1991). Brain and Language, 45, 86-93.
Zurif, E., \& Caramazza, A. (1976). Psycholinguistic structures in aphasia: Studies in syntax and semantics. In H. \& H.A. Whitaker (Eds.), Studies in neurolinguistics (Vol. I, pp. 260-292). New York: Academic Press. 
Table 1:

Semantic Relations Underlying First Word Combinations in English and Italian (adapted from Braine, 1976)

$\begin{array}{lll}\text { Semantic functions } & \text { English examples } & \text { Italian examples } \\ \text { Attention to X } & \text { "See doggie!" } & \text { "Gadda bau" } \\ \text { Property of X } & \text { "Big doggie" } & \text { "Gande bau" } \\ \text { Possession } & \text { "My truck" } & \text { "Mia brum-brum" } \\ \text { Plurality or } & \text { "Two shoe" } & \text { "Due pappe" } \\ \text { Iteration } & \text { "Other cookie" } & \text { "Atto bototto" } \\ \text { Recurrence } & \text { "Daddy bye bye" } & \text { "Papà via" } \\ \text { Disappearance } & \text { "No bath" } & \text { "Bagno no" } \\ \text { Negation or Refusal } & \text { "Mommy do it" } & \text { "Fa mamma" } \\ \text { Actor-Action } & \text { "Baby car" } & \text { "Bimbo casa" } \\ \text { Location } & \text { "Have dat" } & \text { "Dà chetto" } \\ \text { Request } & \end{array}$


Table 2: Examples of speech by two-year-olds in different languages

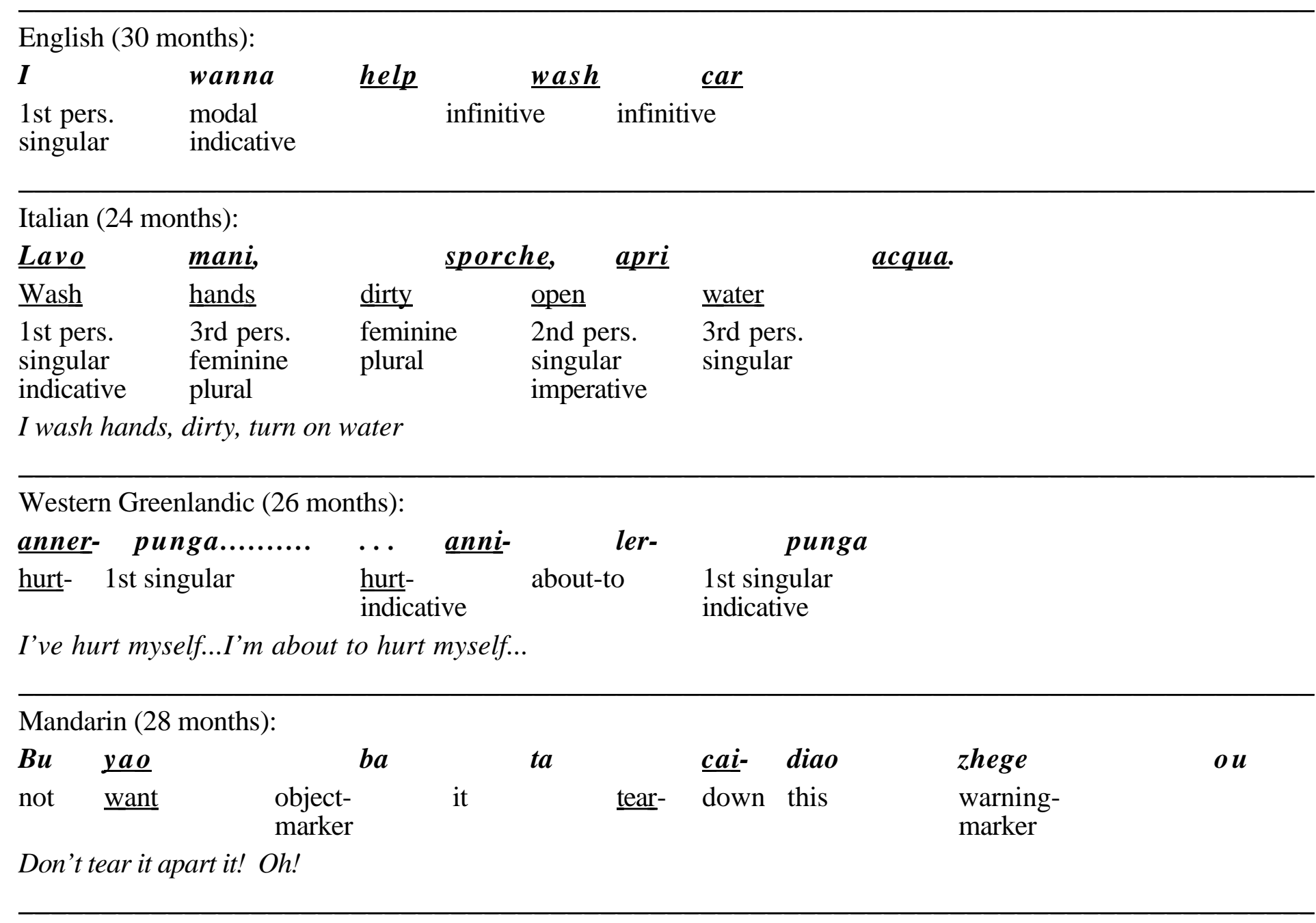


Sesotho (32 months):

$\boldsymbol{o}$ -

$\begin{array}{clllll}\boldsymbol{t l a}- & \underline{\text { hlaj}-} & \boldsymbol{u} \boldsymbol{w}- & \boldsymbol{a} & \boldsymbol{k} \text { e } & \underline{\text { tshehlo }} \\ \text { future } & \underline{\text { stab- }} & \begin{array}{l}\text { passive } \\ \text { marker }\end{array} & \text { mood } & \text { by } & \underline{\text { thorn }} \\ \text { class } 9\end{array}$

subject marker

You'll get stabbed by a thorn.

Japanese (25 months):

Okashi

tabe-

$r u$

tte

Sweets eat

non-

past

marker

say

yut ${ }_{\text {past }} t a$

She said that she'll eat sweets 
Table 3: Utterances reported for English vs. Italian children matched for vocabulary ( $\mathrm{s}=$ singular; $\mathrm{p}=$ plural; $\mathrm{m}=$ masc $; \mathrm{f}=\mathrm{fem}$. $\mathrm{el}=$ elided; $\mathrm{un}=$ gender unmarked; 1st-3rd = person; imp = imperative; dat = dative; ref = reflexive; part = partitive)

\section{ITALIAN}

Female, 24 months, 231 words

Chicca e mamma mangiamo la stessa cosa

Chicca and mamma eat ( 1 st $p l)$ the $\left(f_{s}\right)$ same $\left(f_{s}\right) \operatorname{thing}\left(f_{s}\right)$

Dal dottore no Chicca

To the (ms) doctor(ms) no Chicca

Nonna Silvia cade, bua ginocco, naso, denti

Grandma Silvia falls(3rd s), booboo knee,(ms) nose (ms), teeth(mpl)

Male, 24 months, 364 words

Il papa porta il gelato a Davide

The $(\mathrm{ms})$ daddy $(\mathrm{ms})$ brings(3rd. $s)$ the $(\mathrm{ms})$ icecream $(\mathrm{ms})$ to Davide

Mamma andiamo dalla nonna in campagna con la macchina

Mommy, go (1st. pl) to the (fs) grandma $\left.\left(f_{s}\right)\right)$ in country with the $\left(f_{s}\right)$ car $\left(f_{s}\right)$

Mamma fa il bagno a Davide

Mommy makes(3rd. s) the (ms) bath(ms) to Davide

Male, 24 months, 479 words

Prendiamo l'autobus e andiamo dalla zia

Take(1st. pl. the (el) bus(ms) and go(1st. pl.) to the $\left(f_{s}\right)$ aunt $\left(f_{s}\right)$

Non c'e il sole oggi, mamma?

Not there-is(3rd. s) the (ms) sun(ms) today, Mommy?

La ruspa fa un buco grande grande, e poi se ne va a casa

The $\left(f_{s}\right)$ bulldozer $\left(f_{s}\right)$ makes ( $\left.3 \mathrm{rd} . \mathrm{s}\right)$ a $(\mathrm{ms})$ hole $(\mathrm{ms})$ big(uns) big(uns),

and then (ref) (part) go(3rd. s) to home

Male, 30 months, 590 words

Metti l'acqua in questo bicchiere, l'altro e sporco

Put(2nd. s. imp.) the (el) water(fs) in this(ms) glass(ms), the(el)

other(ms) is(3rds) dirty ( $m s)$

Prendo il mio orso e gli do la pappa

Take(1st. s) the (ms) my (ms) bear(ms) and it(dat) give(1st s) the (fs) food(fs).

Voglio lavarmi i denti con lo spazzolino nuovo

Want(1st. s) to-wash-myself(1st. s ref) the (mpl) teeth(mpl) with the(ms)

toothbrush (ms) new (ms)

\section{ENGLISH}

Female, 24 months, 235 words

Daddy work boat

Baby go night-night

Mommy in there?

Male, 24 months, 352 words

Daddy go work

Happy day to you

Wanna talk to Grandma phone

Male, 24 months, 494 words

Mamma, Megan touched TV

Go bye-bye see grandma, grandpa

I want milk please

Male. 30 months, 595 words

Daddy see lights on the ground, out the window

Alan wants pizza from the pizza store

I got curly hair too 
Table 4:

Order of importance of cues to actor assignment across language (from Bates \& MacWhinney, 1989)

English

Adults: $\quad$ SVO $>$ VOS, OSV $>$ Animacy, Agreement $>$ Stress, Topic

$5-7: \quad$ SVO $>$ Animacy $>$ Agreement $>$ NNV, VNN, Stress

Under 5: $\quad$ SVO $>$ Animacy $>$ Stress, SOV, VSO $>$ Agreement

Italian

Adults: $\quad$ SV Agreement $>$ Clitic Agreement $>$ Animacy $>$ SVO $>$ Stress, Topic

(NNV, VNN interpretable only in combination with stress, clitics)

Under 7: $\quad$ Animacy $>$ SVO $>$ SV Agreement $>$ Clitic Agreement $>\mathrm{SOV}$, VSO

(no interactions of NNV, VNN with stress, clitics)

French

Adults: SV Agreement $>$ Clitic Agreement $>$ Animacy $>$ SVO $>$ Stress

Under 6: $\quad$ SVO $>$ Animacy $>$ VSO, SOV (agreement not tested)

Spanish

Adults: Accusative preposition $>$ SV Agreement $>$ Clitic Agreement $>$ Word Order

(animacy not tested) 
German

Adults: Case > Agreement > Animacy > SOV, VSO, SVO

Dutch

Adults: Case $>\mathrm{SVO}>$ Animacy

Under 10: $\quad$ SVO $>$ Case $>$ Animacy

Serbo-Croatian

Adults: Case > Agreement > Animacy > SVO, VSO, SOV

Under 5: $\quad$ Animacy $>$ Case $>\mathrm{SVO}, \mathrm{VSO}, \mathrm{SOV}>$ Agreement

\section{Hungarian}

Adults: Case $>\mathrm{SV}>$ Agreement $>\mathrm{SVO}$, SOV $>$ Animacy $>\mathrm{V}-\mathrm{O}$ agreement

Under 3: $\quad$ Animacy $>$ Case $>$ SVO $>$ Stress (agreement not tested)

\section{Turkish}

Adults: Case $>$ Animacy $>$ Word Order

Under 2: $\quad$ Case $>$ Word Order (animacy not tested) 
Hebrew

Adults: Case $>$ Agreement $>$ Order

Under 10: $\quad$ Case $>$ Order $>$ Agreement

Warlpiri

Adults: Case > Animacy > Order

Under 5: $\quad$ Animacy $>$ Case $>$ Order

Chinese

Adults: $\quad$ Animacy $>$ SVO

Japanese

Adults: $\quad$ Case $>$ Animacy $>\mathrm{SVO}$ 